\title{
Three novel mutations in $A S I P$ associated with black fibre in alpacas (Vicugna pacos)
}

\author{
N. L. FEELEY, S. BOTTOMLEY AND K. A. MUNYARD* \\ WABRI, School of Biomedical Sciences, Faculty of Health Sciences, Curtin University, Perth, \\ Western Australia, Australia
}

(Revised MS received 28 October 2010; Accepted 8 November 2010; First published online 5 January 2011)

\begin{abstract}
SUMMARY
The coding region of the alpaca Agouti signalling protein ( $A S I P)$ gene was sequenced. It was determined to be 402 nucleotides long and code for a protein that is 133 amino acids long. Eight mutations were identified in a sample of 15 alpaca, five in the coding region and three in the introns flanking the exons. In silico analysis showed that three of the five mutations in the coding sequence, c.325_381del57, c. $292 \mathrm{C}>\mathrm{T}$ and c.353G $>\mathrm{A}$ are probable loss-of-function mutations. The three mutations were strongly associated with black fibre colour, with 0.90 of black alpacas in the current study having two copies of one or another of the mutations. However, not all black animals displayed the putative 'aa' genotype, and almost half of the non-black animals did display that genotype. Contributing factors such as regulatory region mutations, interactions of ASIP with melanocortin-1 receptor (MC1R) and $\alpha$-melanocyte stimulating hormone $(\alpha-\mathrm{MSH})$, the effect of dilution genes and subjective phenotype assignment are discussed. These mutations will allow alpaca breeders to select for or against black, but they do not explain all black phenotypes in this species.
\end{abstract}

\section{INTRODUCTION}

Colour is very important for the alpaca fibre industry because it has a substantial impact on the value of the fibre. Alpacas have more than 22 recognized colour variants and this fact, combined with the paucity of information on alpaca fibre colour inheritance patterns, and subjective phenotype recording methods, have resulted in inefficient prediction of colour outcomes in breeding programmes (Sponenberg 2001; McGregor 2006).

Pigmentation is a complex process with the potential for colour to be affected at any stage from the specification of melanocyte lineage at the neural crest to the export of melanin from the melanocyte (Hoekstra 2006; Thiruvenkadan et al. 2008). Although there are over 300 identified genes that have a known role in mammalian pigmentation, a few key genes have been identified as major regulators of pigment production in mammals (Rieder et al. 2001; Fontanesi et al. 2010). These are the melanocortin-1 receptor $(M C 1 R)$, the $\alpha$-melanocyte stimulating hormone $(\alpha-M S H)$ and the

* To whom all correspondence should be addressed. Email: K.Munyard@curtin.edu.au
Agouti signalling protein $(A S I P)$ genes (Sturm et al. 2001; Rouzaud \& Hearing 2005; Hoekstra 2006). These three genes have been characterized extensively in many mammalian species including mice, humans, horses, sheep, cows, pigs and dogs, and many mutations have been reported that have associations with phenotype variation (Jackson et al. 1994; Rouzaud et al. 2000; Rieder et al. 2001; Sturm et al. 2001; Kerns et al. 2003).

Mammals are only able to produce two types of pigment, eumelanin and pheomelanin, which results in black to brown and red to yellow colours, respectively (Furumura et al. 1996; Rees 2003; Hoekstra 2006). The protein products of the $M C l R, \alpha-M S H$ and $A S I P$ genes, and the interactions between them, control the relative amount, type and location of pigment that is produced (Furumura et al. 1996; Rieder et al. 2001; Rees 2003). Therefore, MC1R, $\alpha-M S H$ and $A S I P$ are the genes primarily responsible for the wide array of pigment variation observed in mammals (Sturm et al. 2001; Hoekstra et al. 2006).

The product of the MC1R gene is the melanocortin1 receptor protein (MC1R), which is expressed on the cell surface of melanocytes (Scott et al. 2002; Newton et al.2005). Initiation of intracellular MC1R signalling 
is induced by the binding of its ligand, the protein product of $\alpha-M S H, \alpha$-MSH (Hearing 2005; Hoekstra 2006; Tully 2007). The MC1R/ $\alpha$-MSH complex activates the adenyl cyclase pathway that leads to increased cyclic-adenosine mono-phosphate (cAMP) levels within the cell. A high level of cAMP is a crucial factor in the initiation of downstream signalling events within the cell leading to stimulation of eumelanin production (Buscà \& Ballotti 2000; Oyehaug et al. 2002).

The ASIP gene encodes for a small, secreted protein, ASIP, $c .133$ amino acids in length which consists of a secretion signal, a lysine-rich basic region and a folded, cysteine rich C-terminus (Hustad et al. 1995; Willard et al. 1995). ASIP is an antagonist of MC1R, and acts specifically to block the activity of the MC1R agonist, $\alpha-\mathrm{MSH}$, and inhibit MC1R activation (Hustad et al. 1995; Willard et al. 1995). When the receptor is in its inactive conformation, cAMP production is reduced or inhibited, and the cell switches to pheomelanin synthesis (Furumura et al. 1996; Le Pape et al. 2008).

The ASIP gene consists of three coding exons, most often termed exons 2, 3 and 4. Many mammals have no reported mutations within the coding region, and in most species the coding region is highly conserved (Siracusa 1994; Chen et al. 1996; Graphodatskaya et al. 2002; McNulty et al. 2005; Royo et al. 2008; Fontanesi et al. 2010). However, non-agouti black in dogs and in Japanese quail is the result of mutation in exon 4 (Kerns et al. 2004; Hiragaki et al. 2008).

Recent research into alpaca fibre colour genetics has included studies on MCIR (Powell et al. 2008; Feeley \& Munyard 2009). Several polymorphisms were identified in $M C 1 R$ that may influence colour in alpacas; however, these polymorphisms were not sufficient to explain all coat colour variation observed in alpacas. There has been no reported research investigating the alpaca $A S I P$ gene and its effects on fibre pigment production. Due to its close interaction with MC1R, information about ASIP is essential for gaining an understanding of the genetic mechanisms controlling colour inheritance in alpacas, an idea that is supported by the fact that alpacas exhibit phenotypes analogous to phenotypes controlled by ASIP in other species (for example black and bay in horses; black and black and tan in dogs). The objectives of the current research were to analyse the coding region of the alpaca $A S I P$ gene for mutations and ascertain their potential effect on pigment production.

\section{MATERIALS AND METHODS}

\section{Animals and DNA extraction}

Blood samples were collected from 94 alpacas (Table 1). Initial sequence analysis was carried out
Table 1. Colour phenotypes of alpacas used in the current study

\begin{tabular}{lc}
\hline \hline Fibre colour & Number of animals \\
\hline Black & 53 \\
Black and tan & 1 \\
Silver-grey & 1 \\
Brown & 13 \\
Fawn & 12 \\
White & 14 \\
Total & 94 \\
\hline \hline
\end{tabular}

on 15 animals (three black, two black and tan, five brown and five fawn). An additional 79 animals, comprising a wider range of colour phenotypes, were subsequently analysed, but only for exon 4 mutations. Fibre colour was determined according to the owners' assessment of the animal. Samples were collected from animals bred in the states of Western Australia, New South Wales and Victoria in Australia. Genomic DNA was extracted from $200 \mu$ of EDTA anticoagulated blood using the AxyPrep Blood Genomic DNA Miniprep Kit (Axygen, Union City, CA, USA) according to the manufacturer's instructions.

\section{Amplification and sequencing of alpaca ASIP and $M C 1 R$}

Polymerase chain reaction (PCR) primers were designed to amplify the three coding exons of the alpaca ASIP gene (Table 2). These primers were based on the alpaca sequence assembly available on the Ensembl database (http://www.ensembl.org/index.html) and were designed to hybridize $c .100 \mathrm{bp}$ outside of the predicted splice sites for these exons, thereby amplifying the complete coding region of alpaca ASIP, and part of the introns of the gene. All PCRs were carried out in an Eppendorf Mastercycler (Eppendorf, North Ryde, New South Wales, Australia), in $10 \mu \mathrm{l}$ reactions containing $67 \mathrm{mmol} / \mathrm{l} \mathrm{Tris} / \mathrm{HCl}(\mathrm{pH} 8 \cdot 8), 16.6 \mathrm{mmol} / 1$ $\left[\mathrm{NH}_{4}\right]_{2} \mathrm{SO}_{4}, 0 \cdot 45 \%(\mathrm{v} / \mathrm{v})$ Triton X-100, $0 \cdot 2 \mathrm{mg} / \mathrm{ml}$ gelatin, $0 \cdot 2 \mathrm{mmol} / \mathrm{l}$ dNTP (Fisher Biotec, Wembley, Western Australia, Australia), $0 \cdot 2 \mu \mathrm{mol} / \mathrm{l}$ each of forward and reverse primer, 1 unit Taq DNA polymerase (Fisher Biotec), $1.5 \mathrm{mmol} / 1 \mathrm{MgCl}_{2}$ and $20 \mathrm{ng}$ genomic DNA. Thermal cycles were: initial denaturation at $95^{\circ} \mathrm{C}$ for $3 \mathrm{~min}$, followed by 30 cycles, each consisting of $94^{\circ} \mathrm{C}$ for $30 \mathrm{~s}$, annealing for $30 \mathrm{~s}$ (Table 2) and $72{ }^{\circ} \mathrm{C}$ for $45 \mathrm{~s}$; with a final extension at $72{ }^{\circ} \mathrm{C}$ for $10 \mathrm{~min}$. Amplified DNA was electrophoresed in 1.5\% $(\mathrm{w} / \mathrm{v})$ agarose gels in TAE buffer, stained with ethidium bromide and visualized by UV transillumination. The PCR products were purified using the AxyPrep PCR Cleanup Kit (Axygen). Amplification of ASIP coding exons from each animal was carried 
Table 2. Primer pairs designed for amplification of ASIP exons from genomic DNA

\begin{tabular}{|c|c|c|c|}
\hline Primer & Sequence $\left(5^{\prime}-3^{\prime}\right)$ & $\begin{array}{l}\text { Product } \\
\text { size (bp) }\end{array}$ & $\begin{array}{c}\text { Annealing } \\
\text { temperature }\left({ }^{\circ} \mathrm{C}\right)\end{array}$ \\
\hline Ex2F & CTCAACTGGGACACTTGTGG & 416 & 60 \\
\hline Ex $2 R$ & AGCACAAAGGAGCTGTGACC & & \\
\hline Ex3F & TCTATTCAGCCAACCCTTCG & 350 & 60 \\
\hline Ex3R & GGTCTGGTCAGAGCTCAAGG & & \\
\hline Ex4F & TAAGTCCGAGCAGGTAGTGG & 560 & 65 \\
\hline Ex4R & AGGGAGCATGTGCGTAGC & & \\
\hline
\end{tabular}

out in five independent $10 \mu$ reactions, which were pooled before purification and sequencing. Sequencing reactions were carried out using ASIP primers for each exon (Table 2) with Big Dye Terminator Technology v3.1 (Applied Biosystems, Mulgrave, Victoria, Australia) and analysed on a 3730 DNA analyser (Applied Biosystems). Genotypes at MC1R were obtained (following the procedures outlined in Feeley \& Munyard 2009) for non-black alpacas in this study who exhibited putative non-functional ASIP mutations.

\section{Sequence assembly and analysis}

Splice sites were determined using the program SpliceView (http://zeus2.itb.cnr.it/ webgene/wwwspliceview. html; verified 19 Nov 2010) coupled with the known bovine and human ASIP exons. Complete ASIP coding region sequences for each animal were compiled using Geneious software (Biomatters, Auckland, New Zealand), and were compared with genes and proteins from other species by GenBank NCBI BLASTn and BLASTx protocols (http://blast.ncbi. nlm.nih.gov/Blast.cgi; verified 19 Nov 2010).

\section{Genotyping ASIP mutations}

Once mutations were identified in alpaca ASIP (Table 3) an additional sample group was genotyped for the four exon 4 polymorphisms (Table 4). The PCRs were carried out as above on an additional 79 animals (Table 1). Amplified DNA was electrophoresed in $1.5 \%(\mathrm{w} / \mathrm{v})$ agarose gels in TAE buffer, stained with ethidium bromide and visualized by UV transillumination. PCR products were then sequenced using Big Dye v3.1 on a 3730 DNA analyser (Applied Biosystems) at Macrogen Inc., South Korea, using primers Ex4F and Ex4R. The deletion was analysed by electrophoresis in $2 \%(\mathrm{w} / \mathrm{v})$ agarose gels in TAE buffer, stained with ethidium bromide and visualized by UV transillumination. Fisher's exact test was used to test for non-random association between mutations and colour.
Table 3. Polymorphisms identified in the alpaca ASIP gene

\begin{tabular}{|c|c|c|}
\hline Polymorphism & Location & Amino acid effect \\
\hline c. $102 \mathrm{G}>\mathrm{A}$ & Exon 2 & Synonymous \\
\hline c. $291 \mathrm{C}>\mathrm{A}$ & Exon 4 & Synonymous \\
\hline Exon $3+34 \mathrm{C}>\mathrm{T}$ & Intron 2 & N/A \\
\hline Exon $3+56 \mathrm{~A}>\mathrm{C}$ & Intron 2 & N/A \\
\hline Exon $4-41 \mathrm{C}>\mathrm{A}$ & Intron 2 & N/A \\
\hline c. $292 \mathrm{C}>\mathrm{T}$ & Exon 4 & R98C \\
\hline c. $353 \mathrm{G}>\mathrm{A}$ & Exon 4 & $\mathrm{R} 118 \mathrm{H}$ \\
\hline c. $325 \_381$ del 57 & Exon 4 & C109-R127del \\
\hline Exon $4+10 \mathrm{C}>\mathrm{T}$ & 3' UTR & N/A \\
\hline Exon $4+38 \mathrm{~A}>\mathrm{G}$ & 3' UTR & N/A \\
\hline
\end{tabular}

\section{Predictive modelling of ASIP}

A multiple alignment of ASIP sequences from 32 different mammalian species was performed using Jalview 2.0 (Waterhouse et al. 2009) with the Muscle algorithm (Edgar 2004) using default values. The web server versions of the scale-invariant feature transform (SIFT; Kumar et al. 2009), iMutant 2.0 (Capriotti et al. 2005), iPTree-STAB (Huang et al. 2007) and PolyPhen (Ramensky et al. 2002) algorithms were used to predict the potential effect of amino acid substitutions on ASIP structure and function. Default values were used for all programs. SIFT is based on sequence conservation and homology, using position-specific scoring matrices. It predicts the effects of amino acid substitution on both structure and function. iMutant 2.0 and iPTreeSTAB use a thermodynamic method and base their predictions on protein stability using the calculated free energy change $(\Delta \Delta G)$ of mutations within the protein sequence. PolyPhen bases its predictions on empirical rules applied to the protein's sequence, phylogenetic and structural information. All methods, except iPTree-STAB, provide an estimate of confidence in their predictions. The signal peptide was detected using the web servers of SignalP (Bendtsen et al. 2004), CoSiDe (http://sigpep.services.came.sbg. 
Table 4. ASIP genotypes of the three significant exon 4 polymorphisms examined in the current study

\begin{tabular}{|c|c|c|c|c|c|}
\hline \multirow{2}{*}{$\begin{array}{l}\text { Putative } \\
\text { ASIP } \\
\text { genotype }\end{array}$} & \multicolumn{3}{|c|}{ Exon 4 genotype } & \multirow[b]{2}{*}{ Colour } & \multirow[b]{2}{*}{$\begin{array}{l}\text { Number } \\
\text { of animals }\end{array}$} \\
\hline & $\begin{array}{c}\text { c. } 292 \mathrm{C}>\mathrm{T} \\
\text { R98C }\end{array}$ & $\begin{array}{c}\text { c. } 353 \mathrm{G}>\mathrm{A} \\
\mathrm{R} 118 \mathrm{H}\end{array}$ & $\begin{array}{l}\text { c. } 325 \_381 \text { del} 57 \\
\text { C109_R127del }\end{array}$ & & \\
\hline \multirow{3}{*}{$a^{1} a^{1}$} & $\mathrm{CC}$ & - & Yes & Black & 21 \\
\hline & & & & Brown & 3 \\
\hline & & & & Fawn & 1 \\
\hline$a^{2} a^{2}$ & $\mathrm{TT}$ & GG & No & Black & 4 \\
\hline \multirow{3}{*}{$a^{3} a^{3}$} & $\mathrm{CC}$ & AA & No & Black & 5 \\
\hline & & & & Brown & 2 \\
\hline & & & & White & 1 \\
\hline \multirow[t]{2}{*}{ AA } & $\mathrm{CC}$ & GG & No & Fawn & 1 \\
\hline & & & & White & 5 \\
\hline \multirow[t]{4}{*}{$a^{2} a^{3}$} & CT & GA & No & Black & 3 \\
\hline & & & & Brown & 1 \\
\hline & & & & Fawn & 1 \\
\hline & & & & White & 2 \\
\hline \multirow[t]{2}{*}{$\mathrm{Aa}^{3}$} & $\mathrm{CC}$ & GA & No & Fawn & 5 \\
\hline & & & & White & 3 \\
\hline \multirow[t]{4}{*}{$\mathrm{Aa}^{2}$} & $\mathrm{CT}$ & GG & No & Black & 1 \\
\hline & & & & Brown & 1 \\
\hline & & & & Fawn & 1 \\
\hline & & & & White & 1 \\
\hline \multirow[t]{5}{*}{$\mathrm{Aa}^{1}$} & $\mathrm{CC}$ & G & Het & Black & $\begin{array}{l}1 \\
4\end{array}$ \\
\hline & & & & Silver-grey & 1 \\
\hline & & & & Brown & 2 \\
\hline & & & & Fawn & 2 \\
\hline & & & & White & 1 \\
\hline \multirow[t]{2}{*}{$a^{1} a^{3}$} & $\mathrm{CC}$ & A & Het & Black & 2 \\
\hline & & & & Brown & 2 \\
\hline \multirow[t]{5}{*}{$a^{1} a^{2}$} & $\mathrm{CT}$ & G & Het & Black & 13 \\
\hline & & & & Black and tan & 1 \\
\hline & & & & Brown & 2 \\
\hline & & & & Fawn & 1 \\
\hline & & & & White & 1 \\
\hline
\end{tabular}

ac.at/; verified 19 Nov 2010) and Phobius (Kall et al. 2007).

\section{RESULTS}

\section{The alpaca ASIP gene}

The complete coding sequence of the alpaca ASIP gene was generated (GenBank accession no. HM768322). Homology with the ASIP gene of other species was confirmed, with the highest sequence homology being to cow, goat and sheep $(89 \%)$ and pig $(88 \%)$. Exon 2 is $160 \mathrm{bp}$, exon 3 is $65 \mathrm{bp}$ and exon 4 is 177 nucleotides in length. The entire coding region is $402 \mathrm{bp}$ long, $6 \mathrm{bp}$ longer than the dog and mouse, $3 \mathrm{bp}$ longer than the human and $6 \mathrm{bp}$ shorter than the cat ASIP coding region. A consensus splice acceptor and splice donor site flanks each coding exon. Exons 2, 3 and 4 contain 54, 40 and 68\% GC (respectively) and the whole coding region is $58 \%$ GC.

\section{The predicted alpaca ASIP protein}

Alpaca ASIP translates into a 133 amino acid predicted protein (Fig. 1) that is 0.83 identical to sheep and cow ASIP and 0.81 identical to the horse and rabbit proteins (see end of this paper for link to supplementary information). The consensus prediction for the signal peptide in ASIP was from residues 1 to 22 by two out of three signal peptide prediction methods. The predicted peptide cleavage site was between residues 22(S) and 23(H). In contrast, Phobius predicted a signal peptide cleavage site between residues 24 and 25 .

A pairwise alignment of the alpaca ASIP sequence with the sequence of an engineered ASIP structure (Protein Data Base ID: 2KZA) showed that they were 0.74 identical in the 53 residue, cysteine rich, C-terminal sequence. All cysteines in the pairwise alignment were exactly aligned. Consequently, it can be inferred by sequence similarity that the disulphide 
(a)

)

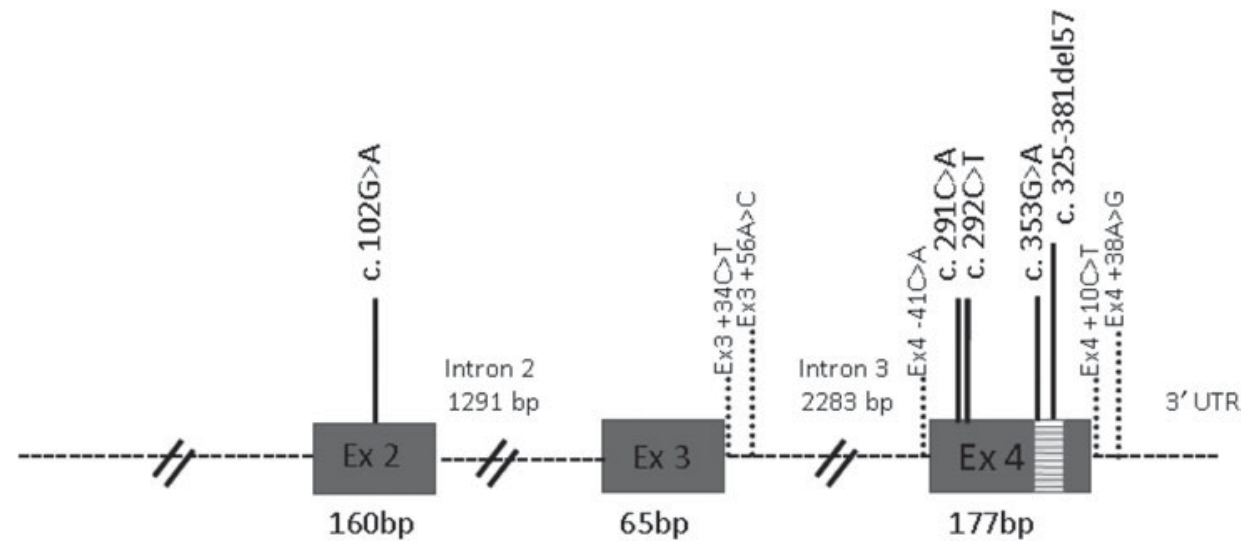

Exon 2

(b)

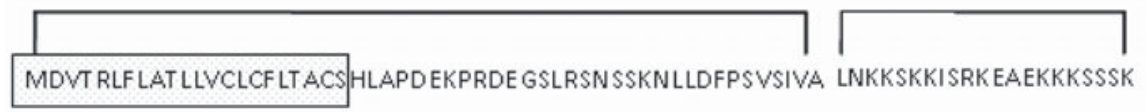

Exon 4

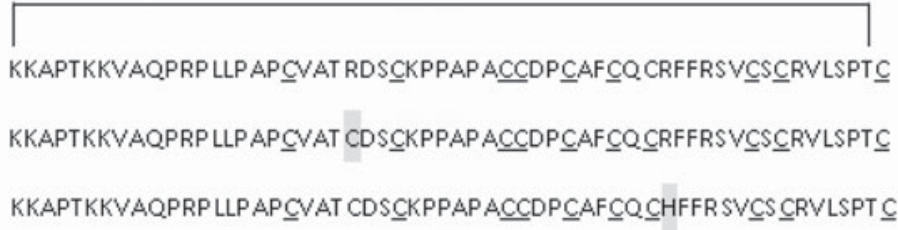

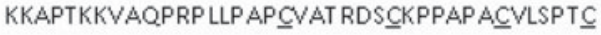

Fig. 1. The alpaca ASIP gene. (a) Coding exons 2, 3 and 4 are shown as solid boxes. Untranslated regions are shown as dashed lines (not to scale). Polymorphisms are shown in the regions where they occur. Indicated intron size was determined from the Ensembl genome assembly. (b) The predicted alpaca wild-type ASIP protein. The conserved cysteine residues in the C-terminus are underlined, the secretion signal is shown as a dotted box. Predicted exon 4 protein sequences for the R98C, R118H (grey boxes) and C109_R127del mutations are shown below the wild-type protein.

bonds in alpaca ASIP are likely to occur at cysteine residue locations [94-109], [101-115], [108-126], [112-133] and [117-124]. The disulphide bond prediction method DBCP (Lin \& Tseng 2010) also predicted disulphide bonds at exactly the same locations in alpaca ASIP.

\section{Mutations in alpaca ASIP and MCIR}

Sequencing of the $A S I P$ coding region in 15 alpacas revealed five polymorphisms (Table 3). Two nonsynonymous single nucleotide polymorphisms (SNPs) were identified in exon 4: c.C292T, predicted to cause an arginine-to-cysteine substitution at codon 98 (R98C; GenBank accession no. HM768323), and c.G353A, predicted to cause an arginine-to-histidine substitution at codon 118 (R118H; GenBank accession no. HQ008273). A $57 \mathrm{bp}$ deletion was also discovered in exon 4. This deletion, occurring at nucleotides 325-381 (c.325_381del57; GenBank accession no. HM768324), is predicted to result in 19 of the last 25 amino acids being absent from the mature protein (p.C109_R127del). In addition, two synonymous mutations; c.G102A in exon 2 (p.G34) and c.C291A in exon 4 (p.T291) were identified. Four haplotypes involving these mutations were observed in this group of alpacas, and these haplotypes existed in ten different combinations (Table 4). While no match occurred between any fibre colour and any single ASIP genotype in the 94 animals studied (Table 4) there was strong association between the homozygous state of each mutation and black colour, 
as well as between the combined alleles and black colour (Fisher's exact test for c.325_381del57 $P<0.001$; for c. $292 \mathrm{C}>\mathrm{T} \quad P=0.039$; for c. $353 \mathrm{G}>\mathrm{A}$ $P=0.024$; and for all combined $P<0 \cdot 001$ ). Forty eight of the 53 black animals were either homozygous for C109_R127del (allele $a^{1}$ ), the T allele of R98C $\left(a^{2}\right)$, the A allele of $\mathrm{R} 118 \mathrm{H}\left(\mathrm{a}^{3}\right)$ or were heterozygous for $\mathrm{a}$ combination of two of these mutations. However, 18 of the 41 non-black animals also exhibited some of these same genotype combinations. These animals exhibited a range of MC1R genotypes (Table 5). An additional five SNPs were identified in the non-coding regions flanking the exons (Table 3).

\section{Predicted functional effect of ASIP mutations}

The arginine residues at positions 98 and 118 in the alpaca ASIP sequence are highly conserved in all ASIP sequences aligned from 32 different mammalian species (see end of the paper for link to supplementary material). All amino acid substitution prediction methods used predicted that the R98C and R118H amino acid substitutions are potentially damaging to ASIP structure or function (Table 6). Only the SIFT method labelled its prediction as 'low confidence'. Therefore, it is proposed that the mutations R98C, R118H and C109-R127del are all loss of function non-agouti equivalent ' $\mathrm{a}$ ' mutations for alpaca ASIP.

\section{DISCUSSION}

Three novel mutations in exon 4 of the alpaca $A S I P$ gene have been identified that are each predicted to cause a loss of function in the protein. Exon 4 codes for the last 40 amino acid residues of ASIP, which constitute the C-terminal domain and the majority of the residues are responsible for protein activity and receptor binding (Dinulescu \& Cone 2000; Miltenberger et al. 2002). It has been reported that the ten cysteine residues within the $\mathrm{C}$-terminus are involved in a network of five disulphide bonds that acts to stabilize the protein (McNulty et al. 2005; Yu $\&$ Millhauser 2007) and form a unique fold motif known as an inhibitor cysteine knot (ICK; McNulty et al. 2005; Yu \& Millhauser 2007). The spacing of the ten cysteine residues in ASIP is strictly conserved throughout all mammals that have been investigated (Miltenberger et al. 2002; McNulty et al. 2005; Yu \& Millhauser 2007). The particular fold structure of the ICK allows for presentation of three important conserved residues, $\operatorname{Arg}_{116} \mathrm{Phe}_{117} \mathrm{Phe}_{118}$, in order to facilitate MC1R interaction and binding (Miltenberger et al. 2002). This structure can therefore be assumed to be essential for correct ASIP functioning. Animals carrying C109_Rdel19 (aka $\mathrm{a}^{1}$ ) are missing six of these ten conserved cysteine residues. This would almost certainly prevent tertiary structures, such as the ICK,
Table 5. MC1R Genotypes of non-black animals with a genotypes

\begin{tabular}{llcl}
\hline \hline $\begin{array}{l}\text { Putative } \\
\begin{array}{l}\text { ASIP } \\
\text { genotype }\end{array}\end{array}$ & Colour & $\begin{array}{c}\text { Number of } \\
\text { animals }\end{array}$ & $\begin{array}{c}\text { MC1R } \\
\text { genotype }\end{array}$ \\
\hline $\mathrm{a}^{1} \mathrm{a}^{1}$ & Brown & 3 & EE, Ee, ee \\
& Fawn & 1 & Ee \\
$\mathrm{a}^{3} \mathrm{a}^{3}$ & Brown & 2 & Ee ee \\
& White & 1 & Ee \\
$\mathrm{a}^{2} \mathrm{a}^{3}$ & Brown & 1 & Ee \\
& Fawn & 1 & Ee \\
& White & 2 & Ee Ee \\
$\mathrm{a}^{1} \mathrm{a}^{3}$ & Brown & 2 & Ee ee \\
$\mathrm{a}^{1} \mathrm{a}^{2}$ & Black and & 1 & Ee \\
& tan & & \\
& Brown & 2 & Ee ee \\
& Fawn & 1 & ee \\
& White & 1 & EE \\
\hline \hline
\end{tabular}

Table 6. Potential effect of amino acid substitution on ASIP structure or function

\begin{tabular}{|c|c|c|}
\hline \multirow{2}{*}{$\begin{array}{l}\text { Amino acid } \\
\text { substitution } \\
\text { prediction } \\
\text { method }\end{array}$} & \multicolumn{2}{|c|}{ Amino acid substitution } \\
\hline & $\mathrm{R} 98 \mathrm{C}$ & $\mathrm{R} 118 \mathrm{H}$ \\
\hline SIFT & $\begin{array}{l}\text { Likely to affect } \\
\text { function (low } \\
\text { confidence) }\end{array}$ & $\begin{array}{l}\text { Likely to affect } \\
\text { function (low } \\
\text { confidence) }\end{array}$ \\
\hline iMutant 2.0 & $\begin{array}{l}\text { Decrease in } \\
\text { stability of } \\
\text { structure (high } \\
\text { confidence) }\end{array}$ & $\begin{array}{l}\text { Decrease in } \\
\text { stability of } \\
\text { structure (high } \\
\text { confidence) }\end{array}$ \\
\hline iPTree-STAB & $\begin{array}{l}\text { Destabilizing* to } \\
\text { structure }\end{array}$ & $\begin{array}{l}\text { Destabilizing* to } \\
\text { structure }\end{array}$ \\
\hline PolyPhen & $\begin{array}{l}\text { Probably } \\
\text { damaging* to } \\
\text { structure and } \\
\text { function (high } \\
\text { confidence) }\end{array}$ & $\begin{array}{l}\text { Possibly } \\
\text { damaging* to } \\
\text { structure and } \\
\text { function (medium } \\
\text { confidence) }\end{array}$ \\
\hline
\end{tabular}

* The terms 'destabilizing', 'probably damaging' and 'possibly damaging' are used by the respective methods to describe the effect of the amino acid substitution.

from being formed correctly. With this type of disruption to the protein it is almost certain that function is eliminated.

About half of all known disease-causing mutations result from amino acid substitutions, and automated prediction methods can be used to identify potentially damaging substitutions ( $\mathrm{Ng} \&$ Henikoff 2006). The current study used four automated methods to derive a consensus view on the potential effect of the two observed amino acid substitutions on ASIP structure 
and function. It is preferable to use more than one prediction method, based on different assumptions and algorithms, because this gives increased support for any inference that may be made on the functional or structural significance of an amino acid substitution. In all cases the automated methods predicted a potentially damaging or destabilizing effect on ASIP structure or function for both SNPs (Table 6). Only the SIFT method labelled its prediction as 'low confidence'. The SIFT method depends on sequence diversity to generate confidence values and there was insufficient sequence diversity in the sequence alignment generated by SIFT (which uses PsiBlast to find and align, functionally related sequences). This is a common issue with prediction algorithms that depend on sequence conservation and is understandable given the highly conserved nature of the ASIP sequence.

There are a number of ways in which these SNPs might cause a loss of function in ASIP. The R98C polymorphism results in the substitution of a cysteine for a histidine in the highly conserved C-terminus of the protein. Previous studies have reported that the loss of even one of these highly conserved cysteine residues is sufficient to abolish the activity of the protein (Perry et al. 1995; Miltenberger et al. 2002). The addition of another cysteine residue in this region is predicted to disrupt the formation of this essential tertiary structure and be responsible for a loss of function of the protein. Protein alignment results suggest that the R98C polymorphism in alpacas is the same as the R96C polymorphism present in dogs (Kerns et al. 2004), due to the upstream difference of two amino acids between the two proteins. The R96C mutation in dogs has been shown to be a loss of function mutation resulting in non-agouti black (Kerns et al. 2004). The similarity between these polymorphisms further supports the current in silico predictions that $\mathrm{R} 98 \mathrm{C}$ has a similar affect in alpacas.

The residues $\mathrm{Arg}_{116} \mathrm{Phe}_{117} \mathrm{Phe}_{118}$ have an essential role in protein interactions of the C-terminal domain (Miltenberger et al. 2002; McNulty et al. 2005). When correctly folded, these are the binding determinants of the protein and they facilitate direct interaction with Melanocortin receptors (Miltenberger et al. 2002; McNulty et al. 2005). This suggests that the amino acid sequence of this domain and the correct structural folds are important determinants for protein function. The $\mathrm{R} 118 \mathrm{H}$ substitution is usually considered a conservative substitution according to the Blosum62 evolutionary matrix (Henikoff \& Henikoff 1992) and this is understandable given the similar physicochemical properties of arginine and histidine. However, any change in a highly conserved region has the potential to be detrimental to the protein's structure or function. The conserved $\mathrm{Arg}_{116} \mathrm{Phe}_{117} \mathrm{Phe}_{118}$ amino acids are homologous to residues $\mathrm{Arg}_{118} \mathrm{Phe}_{119} \mathrm{Phe}_{120}$ in alpaca ASIP. Therefore, the
$\mathrm{R} 118 \mathrm{H}$ mutation results in a His-Phe-Phe combination present in the active loop (instead of the conserved Arg-Phe-Phe combination) which may prevent ASIP interaction with MC1R, resulting in a loss-of-function variant. However, functional studies, such as testing the effect of these proteins on receptor signalling in vitro or RNAi in mouse models, are needed to confirm that these mutations are affecting ASIP function. It is interesting to note that the three exon 4 mutations probably occurred in historically independent populations. The $\mathrm{R} 118 \mathrm{H}$ mutation cannot exist in combination with C109_T127del19, and the $\mathrm{T}$ allele of $\mathrm{R} 98 \mathrm{C}$ was never found in combination with the deletion, nor with the A allele of $\mathrm{R} 118 \mathrm{H}$. Only four haplotypes were present in the sample of alpacas used in the current study: C,G,No, C,Yes, T, G,No and C,A,No. Black alpacas are considered to be sacred in South America, and are still sacrificed to the Gods (Bolin 1998; J. C. Wheeler, personal communication). Therefore, historically, any new mutations causing black animals to occur would have been preserved by selective breeding.

It would be expected that animals that are homozygous for any of the non-functional ASIP alleles would have a black phenotype. This is largely consistent with the current data (Table 4): 48 out of 53 black animals were homozygous for $\mathrm{a}^{1}, \mathrm{a}^{2}$ or $\mathrm{a}^{3}$, or were heterozygous for two of these alleles. The five animals that were black in phenotype but did not carry two putative black alleles could have as yet undiscovered mutations in ASIP exons 2 or 3 , regulatory mutations leading to decreased ASIP expression, or dominant mutations at another gene (e.g. MC1R or $\beta$-defensin).

Almost half of the non-black animals were homozygous for the putative non-functional mutations. There are four reasons why non-black animals might carry a black genotype. The first is that a nonfunctional $M C 1 R$ genotype is also present (i.e. ee), thus the specific $A S I P$ allele is irrelevant. MC1R and ASIP have an epistatic relationship where a fully functioning MC1R receptor is necessary for the $A S I P$ alleles to be expressed (Furumura et al. 1996; Hoekstra 2006). If MC1R is non-functional then it cannot be activated or inactivated by either of the two alternate ligands. It will therefore only express pheomelanin, and the ASIP alleles will be masked. Just over one-third of the non-black 'aa' animals are homozygous for the putative non-functional MC1R allele 'e' (Table 5; Feeley \& Munyard 2009); however, others were not. Secondly, if $\alpha$-MSH is also nonfunctional, then MC1R will receive no signal from either its agonist or antagonist, and will revert to pheomelanin production.

A third possible explanation is that dilution genes are having an effect on the underlying colour. The dilution genes MATP and TYR have been investigated in alpacas, but no mutations were found that 
were linked with colour variation (Cransberg \& Munyard 2009). The mutation responsible for the Champagne dilution in horses has recently been identified in SLC36A1 (Cook et al. 2008). This mutation renders black animals brown, and chestnut animals pale golden. Another strong candidate dilution gene is TYRP1, which is known to change black eumelanin to brown eumelanin in many species (e.g. dogs: Schmutz et al. 2002; cows: Berryere et al. 2003; sheep: Gratten et al. 2007). The current authors have found no report of any investigation of these two genes in alpacas.

The fourth potential reason why 'aa' alpacas might be non-black is also a reason why some black animals are not 'aa': subjective phenotype assignment. In the current authors' experience there is considerable variation in the words used to describe similarly coloured alpacas. For instance, one breeder would call a faded black animal brown, while another would call it black. Similar problems also occur when assigning colours to paler animals. It is imperative that the industry adopts an objective way to measure phenotype, perhaps following the simple melanin analysis methods developed by Ito et al. (2000).

While black alleles have been identified in the coding regions of the gene, there is almost certainly additional variation in the regulatory regions of alpaca $A S I P$ that leads to other phenotypes in this species. Alpacas with phenotypes resembling black and tan dogs and bay horses are common, and samples of fibre banded in a hair-cycle specific manner have been observed. It has been shown in several studies that $A S I P$ has a complex structure including different regulatory elements which are involved in expression of the gene in region-specific and cyclespecific ways (Dinulescu \& Cone 2000; Fontanesi et al. 2009). Royo et al. (2008) and Gratten et al. (2010) demonstrated that the regulatory exons of ASIP are important in controlling expression in different breeds of sheep. Norris \& Whan (2008) found that the white phenotype in sheep is dependent on a partial duplication of the regulatory region of ASIP.

The mutation found in exon 2 is a synonymous SNP resulting in no predicted structural changes, and it was polymorphic in every colour group represented in the current sample set. Therefore, although it occurs in the region that codes for the signal sequence and part of the lysine-rich basic region (Hustad et al. 1995; Willard et al. 1995), it is almost certainly only a population polymorphism. In conclusion, the three novel loss-of-function $A S I P$ mutations identified in the current study can be used by alpaca breeders to decrease the frequency of black animals in their herd, by selecting against animals carrying any of the mutations. It will also allow breeders of black alpacas to retain the desired colour, increase their gene pool, and potentially improve the quality of fibre, by identifying high-quality non-black animals that carry black. However, these mutations neither explain all instances of black nor all the phenotypic variation that is possible in $A S I P$.

Supplementary material is available for this paper. http://journals.cambridge.org/AGS

\section{REFERENCES}

Bendtsen, J. D., Nielsen, H., von Heijne, G. \& Brunak, S. (2004). Improved prediction of signal peptides: SignalP 3.0. Journal of Molecular Biology 340, 783-795.

Berryere, T. G., Schmutz, S. M., Schimpf, R. J., Cowan, C. M. \& Potter, J. (2003). TYRP1 is associated with dun coat colour in Dexter cattle or how now brown cow? Animal Genetics 34, 169-175.

Bolin, I. (1998). Rituals of Respect: The Secret of Survival in the High Peruvian Andes. Austin, TX: University of Texas Press.

Buscà, R. \& Ballotti, R. (2000). Cyclic AMP a key messenger in the regulation of skin pigmentation. Pigment Cell Research 13, 60-69.

Capriotti, E., Fariselli, P. \& Casadio, R. (2005). I-Mutant2.0: predicting stability changes upon mutation from the protein sequence or structure. Nucleic Acids Research 33 (Suppl. 2), W306-W310.

Chen, Y., Duhl, D. M. J. \& Barsh, G. S. (1996). Opposite orientations of an inverted duplication and allelic variation at the mouse agouti locus. Genetics 144, 265-277.

Cook, D., Brooks, S., Bellone, R. \& Bailey, E. (2008). Missense mutation in exon 2 of SLC36A1 responsible for champagne dilution in horses. PLoS Genetics 4, e1000195. doi:10.1371/journal.pgen.1000195
Cransberg, R. \& Munyard, K. A. (2009) Polymorphisms detected in the tyrosinase and MATP (SLC45A2) genes did not explain coat colour dilution in a sample of alpaca (Vicugna pacos). In Matching Genetics and Environment: A New Look at an Old Topic. Proceedings of the 18th Conference of the Association for the Advancement of Animal Breeding and Genetics, Barossa Valley, South Australia, Australia, 28 Sept-1 Oct 2009 (Ed. B. P. B. R. Alex Safari), pp. 520-523. South Australia: Association for the Advancement of Animal Breeding and Genetics.

Dinulescu, D. M. \& Cone, R. D. (2000). Agouti and agoutirelated protein: analogies and contrasts. Journal of Biological Chemistry 275, 6695-6698.

EdgAR, R. C. (2004). MUSCLE: multiple sequence alignment with high accuracy and high throughput. Nucleic Acids Research 32, 1792-1797.

Feeley, N. L. \& Munyard, K. A. (2009). Characterisation of the melanocortin-1 receptor gene in alpaca and identification of possible markers associated with phenotypic variations in colour. Animal Production Science 49, 675-681.

Fontanesi, L., Beretti, F., Riggio, V., Gomez Gonzalez, E., Dall'Olio, S., Davoli, R., Russo, V. \& Portolano, B. (2009). Copy number variation and missense mutations of the agouti signaling protein 
(ASIP) gene in goat breeds with different coat colors. Cytogenetic and Genome Research 126, 333-337.

Fontanesi, L., Beretti, F., Riggio, V., Dall'Olio, S., Calascibetta, D., Russo, V. \& Portolano, B. (2010). Sequence characterization of the melanocortin 1 receptor (MC1R) gene in sheep with different coat colours and identification of the putative e allele at the ovine extension locus. Small Ruminant Research 91, 200-207.

Furumura, M., Sakai, C., Abdel-Malek, Z., Barsh, G. S. \& Hearing, V. J. (1996). The interaction of agouti signal protein and melanocyte stimulating hormone to regulate melanin formation in mammals. Pigment Cell Research $\mathbf{9}$, 191-203.

Graphodatskaya, D., Joerg, H. \& Stranzinger, G. (2002). Molecular and pharmacological characterisation of the MSH-R alleles in Swiss cattle breeds. Journal of Receptor and Signal Transduction Research 22, 421-430.

Gratten, J., Beraldi, D., Lowder, B. V., McRae, A. F., Visscher, P. M., Pemberton, J. M. \& Slate, J. (2007). Compelling evidence that a single nucleotide substitution in TYRPI is responsible for coat-colour polymorphism in a free-living population of Soay sheep. Proceedings of the Royal Society B: Biological Sciences 274, 619-626.

Gratten, J., Pilkington, J. G., Brown, E. A., Beraldi, D., Pemberton, J. M. \& Slate, J. (2010). The genetic basis of recessive self-colour pattern in a wild sheep population. Heredity 104, 206-214.

Hearing, V. J. (2005). Biogenesis of pigment granules: a sensitive way to regulate melanocyte function. Journal of Dermatological Science 37, 3-14.

Henikoff, S. \& Henikoff, J. G. (1992). Amino acid substitution matrices from protein blocks. Proceedings of the National Academy of Sciences of the USA 89, 10915-10919.

Hiragaki, T., Inoue-Murayama, M., Miwa, M., Fujiwara, A., Mizutani, M., Minvielle, F. \& Ito, S. I. (2008). Recessive black is allelic to the yellow plumage locus in Japanese quail and associated with a frameshift deletion in the ASIP gene. Genetics 178, 771-775.

Hoekstra, H. E. (2006). Genetics, development and evolution of adaptive pigmentation in vertebrates. Heredity 97, 222-234.

Hoekstra, H. E., Hirschmann, R. J., Bundey, R. A., Insel, P. A. \& Crossland, J. P. (2006). A single amino acid mutation contributes to adaptive beach mouse color pattern. Science 313, 101-104.

Huang, L. T., Gromina, M. M. \& Ho, S. Y. (2007). iPTREE-STAB: interpretable decision tree based method for predicting protein stability changes upon mutations. Bioinformatics 23, 1292-1293.

Hustad, C. M., Perry, W. L., Siracusa, L. D., Rasberry, C., Cobb, L., Cattanach, B. M., Kovatch, R., Copeland, N. G. \& Jenkins, N. A. (1995). Molecular genetic characterization of six recessive viable alleles of the mouse agouti locus. Genetics 140, 255-265.

Ito, S., Wakamatsu, K. \& Ozeki, H. (2000). Chemical analysis of melanins and its application to the study of the regulation of melanogenesis. Pigment Cell Research 13 (Suppl. 8), 103-109.

JACKSON, I. J., BudD, P., Horn, J. M., Johnson, R., Raymond, S. \& Steel, K. (1994). Genetics and molecular biology of mouse pigmentation. Pigment Cell Research 7, 73-80.
Kall, L., Krogh, A. \& Sonnhammer, E. L. (2007). Advantages of combined transmembrane topology and signal peptide prediction - the Phobius web server. Nucleic Acids Research 35 (Web Server issue), W429-W432.

Kerns, J. A., Olivier, M., Lust, G. \& Barsh, G. S. (2003). Exclusion of melanocortin-1 receptor (Mclr) and Agouti as candidates for dominant black in dogs. The Journal of Heredity 94, 75-79.

Kerns, J. A., Newton, J., Berryere, T. G., Rubin, E. M., Cheng, J. F., Schmutz, S. M. \& Barsh, G. S. (2004). Characterization of the dog Agouti gene and a nonagoutimutation in German Shepherd Dogs. Mammalian Genome 15, 798-808.

Kumar, P., Henikoff, S. \& NG, P. C. (2009). Predicting the effects of coding non-synonymous variants on protein function using the SIFT algorithm. Nature Protocols 4, 1073-1081.

Le Pape, E., Wakamatsu, K., Ito, S., Wolber, R. \& Hearing, V. J. (2008). Regulation of eumelanin/pheomelanin synthesis and visible pigmentation in melanocytes by ligands of the melanocortin 1 receptor. Pigment Cell and Melanoma Research 21, 477-486.

Lin, H.-H. \& TsenG, L.-Y. (2010). DBCP: a web server for disulfide bonding connectivity pattern prediction without the prior knowledge of the bonding state of cysteines. Nucleic Acids Research 38 (Suppl. 2), W503W507.

McGregor, B. A. (2006). Production, attributes and relative value of alpaca fleeces in southern Australia and implications for industry development. Small Ruminant Research 61, 93-111.

McNulty, J. C., Jackson, P. J., Thompson, D. A., Chai, B., Gantz, I., Barsh, G. S., Dawson, P. E. \& Millhauser, G. L. (2005). Structures of the agouti signaling protein. Journal of Molecular Biology 346, 1059-1070.

Miltenberger, R. J., Wakamatsu, K., Ito, S., Woychik, R. P., Russell, L. B. \& Michaud, E. J. (2002). Molecular and phenotypic analysis of 25 recessive, homozygous-viable alleles at the mouse agouti locus. Genetics 160, 659-674.

Newton, R. A., Smit, S. E., Barnes, C. C., Pedley, J., Parsons, P. G. \& Sturm, R.A. (2005). Activation of the cAMP pathway by variant human MC1R alleles expressed in HEK and in melanoma cells. Peptides 26, 1818-1824.

Ng, P. C. \& Henikoff, S. (2006). Predicting the effects of amino acid substitutions on protein function. Annual Review of Genomics and Human Genetics 7, 61-80.

Norris, B. J. \& Whan, V.A. (2008). A gene duplication affecting expression of the ovine ASIP gene is responsible for white and black sheep. Genome Research $\mathbf{1 8}$, $1282-1293$.

Oyehaug, L., Plahte, E., Vage, D. I. \& Omholt, S. W. (2002). The regulatory basis of melanogenic switching. Journal of Theoretical Biology 215, 449-468.

Perry, W. L., Hustad, C. M., Swing, D. A., Jenkins, N. A. \& Copeland, N. G. (1995). A transgenic mouse assay for agouti protein activity. Genetics 140, 267-274.

Powell, A. J., Moss, M. J., Tree, L.T., Roeder, B. L., Carleton, C. L., Campbell, E. \& Kooyman, D. L. (2008). Characterization of the effect of Melanocortin 1 Receptor, a member of the hair color genetic locus, in alpaca (Lama pacos) fleece color differentiation. Small Ruminant Research 79, 183-187. 
Ramensky, V., Bork, P. \& Sunyaev, S. (2002). Human nonsynonymous SNPs: server and survey. Nucleic Acids Research 30, 3894-3900.

ReEs, J. L. (2003). Genetics of hair and skin color. Annual Review of Genetics 37, 67-90.

Rieder, S., Taourit, S., Mariat, D., Langlois, B. \& Guerin, G. (2001). Mutations in the agouti (ASIP), the extension (MC1R), and the brown (TYRP1) loci and their association to coat color phenotypes in horses (Equus caballus). Mammalian Genome 12, 450-455.

Rouzaud, F. \& Hearing, V. J. (2005). Regulatory elements of the melanocortin 1 receptor. Peptides 26, 1858-1870.

Rouzaud, F., Martin, J., Gallet, P. F., Delourme, D., Goulemot-Leger, V., Amigues, Y., Menissier, F., Leveziel, H., Julien, R. \& Oulmouden, A. (2000). A first genotyping assay of French cattle breeds based on a new allele of the extension gene encoding the melanocortin-1 receptor (Mc1r). Genetics Selection Evolution 32, 511-520.

Royo, L. J., Alvarez, I., Arranz, J. J., Fernandez, I., Rodriguez, A., Perez-Pardal, L. \& Goyache, F. (2008). Differences in the expression of the ASIP gene are involved in the recessive black coat colour pattern in sheep: evidence from the rare Xalda sheep breed. Animal Genetics 39, 290-293.

Schmutz, S. M., Berryere, T. G. \& Goldfinch, A. D. (2002). TYRP1 and MC1R genotypes and their effects on coat color in dogs. Mammalian Genome 13, 380-387.

Scott, M. C., Wakamatsu, K., Ito, S., Kadekaro, A. L., Kobayashi, N., Groden, J., Kavanagh, R.,
Takakuwa, T., Virador, V., Hearing, V. J. \& AbdelMALEK, Z. A. (2002). Human melanocortin 1 receptor variants, receptor function and melanocyte response to UV radiation. Journal of Cell Science 115, 2349-2355.

Siracusa, L. D. (1994). The agouti gene: turned on to yellow. Trends in Genetics 10, 423-428.

SponenberG, P. (2001). Some educated guesses on color genetics of alpacas. Alpaca Registry Journal 6, 4-15.

Sturm, R. A., Teasdale, R. D. \& Box, N. F. (2001). Human pigmentation genes: identification, structure and consequences of polymorphic variation. Genetics 277, 49-62.

Thiruvenkadan, A.K., Kandasamy, N. \& Panneerselvam, S. (2008). Coat colour inheritance in horses. Livestock Science 117, 109-129.

Tully, G. (2007). Genotype versus phenotype: human pigmentation. Forensic Science International: Genetics 1, $105-110$.

Waterhouse, A. M., Procter, J. B., Martin, D. M., Clamp, M. \& Barton, G. J. (2009). Jalview Version 2 a multiple sequence alignment editor and analysis workbench. Bioinformatics 25, 1189-1191.

Willard, D. H., Bodnar, W., Harris, C., Kiefer, L., Nichols, J.S., Blanchard, S., Hoffman, C., Moyer, M., Burkhart, W., Weiel, J., Luther, M. A., Wilkinson, W. O. \& Rocque, W. J. (1995). Agouti structure and function: characterization of a potent alpha-melanocyte stimulating hormone receptor antagonist. Biochemistry 34, 12341-12346.

Yu, B. \& Millhauser, G. L. (2007). Chemical disulfide mapping identifies an inhibitor cystine knot in the agouti signaling protein. FEBS Letters 581, 5561-5565. 